\title{
PREPARATION AND PROPERTIES OF DIFFERENT FUNCTIONAL GROUP CONTAINING STYRENE BUTADIENE RUBBER
}

\author{
M.T.RAMESAN*AND T. ANIL KUMAR
}

Department of Chemistry, University of Calicut, Calicut University. P.O.,Kerala, India 673 635, Tel: +91 4942401144 *413.Fax: +914942400269.

(Received 26 February 2008 - Accepted 4 November 2008)

\begin{abstract}
Chemically modified styrene butadiene rubber (SBR) with nitro and chloro functionalities are prepared by the nitromercuration reaction of SBR through a phase transfer catalyst. Activation energy for this chemical reaction calculated from the time temperature data on the chemical reaction by the measurement of percentage of chlorine indicated that the reaction proceeded according to fist order kinetics. The chemical modification is characterized by FTIR, UV, NMR studies reveal the attachment functional group such as nitro and chloro group to the double bond of butadiene moiety. The glass transition temperature of the functionalized SBR is analyzed using differential scanning calorimetry. Thermogravimetric analysis (TGA) of the modified SBR is investigated in order to study the basic decomposition pattern and thermal stability of the materials. Chemical modification of SBR is accompanied by a reduction of double bond which imparts excellent tensile strength. The flame resistances of the modified samples are analyzed by the limiting oxygen index value (LOI) and the result of the studies show that as the level modification increases the tendency of ealstomeric material to burn decreases.
\end{abstract}

Keywords: Styrene butadiene rubber, nitromercuration, activation energy, glass transition, thermal, flammability, mechanical properties

\section{INTRODUCTION}

The producers of general purpose synthetic rubbers have put a great deal of effort into the equipping of such rubbers with chemically functional groups along the polymer backbone chains. The purpose has been manifold, ranging from the improvement of green strength and tack to the provision of sites for novel forms of crosslinking, grafting, antioxidant activity and even pharmacological properties. Usually a route to such functionalisation is to incorporate small amounts of monomer carrying desired group in the polymerization process ${ }^{1-6}$. However, polymerization with different functional groups will be expensive and therefore must be used only cheap reagent can be used for macro modification on elsatomers with quite new physical properties.

Synthetic rubber have made a great contribution to many industries, almost all are combustible in air. SBR is one of the elastomer which is widely used in tire industry and in underground coal mining, carpet underlay and car floor mats among other uses 7,8 . However, it has poor green strength and poor resistance against thermo oxidative degradation. Green strength which is cohesiveness in stretched uncured rubber compound is of great importance especially in the processing of tires. Many attempts have been carried out to increase the green strength of SBR and also to improve its oxidative and oil resistance. One attempt to increase the green strength is by the introduction of carbonyl during polymerization ${ }^{9}$. Another method is by introduction of tertiary amine containing monomers during polymerization followed by reaction with dihalides to form a small number of labile croslinks ${ }^{10,11}$. The technique of anionic polymerization using modified alkyl lithium initiators has been used to prepare high vinyl SBR ${ }^{12,13}$. Great attention has been paid to modifying SBR's combustion characteristics. Several approaches were made to decrease the tendency of elastomeric material to burn ${ }^{14-17}$.

Resistance to thermo-oxidative degradation is another important criteria to be satisfied for rubber products used in outdoor applications ${ }^{18}$. It is well known that the degradation of rubber is due to its reaction with molecular oxygen. This reaction can be suppressed by reducing the double bonds, or by introduction of functional groups that can deactivate the double bonds. The introduction of polar groups also brings about enhancement in resistance to oil, ozone, flame and solvents. Particular attention will be focused to develop easily functionalisable smart polymers with optoelectronic properties by introducing functional group like azo and nitro group in the polymer chain by removing the easily labile mercuric chloride. Thus, this paper describes:(a) synthesis and kinetics of functional groups containing SBR (b) characterization of modified SBR using spectroscopic technique such as Fourier Transform Infrared Spectroscopy (FTIR), Fourier Transform Nuclear Magnetic Spectroscopy (FTNMR) and UV spectroscopy (c) glass transition temperature and thermal stability (d) flame resistance and tensile strength of the modified SBR.

\section{EXPERIMENTAL}

\section{Materials}

Styrene butadiene rubber (Synaprene 1502) has been obtained from Synthetics and Chemicals Ltd., Bareilly, U.P., India. Toluene, mercuric chloride, sodium nitrite, tetra butyl ammonium bromide, isopropyl alcohol are of reagent grade and supplied by Merck India Ltd., Mumbai.

IR spectra of samples are recorded with a Jasco Model No. 4100 Fourier transform infrared spectrophotometer, using thin film of polymer. UV spectra of the samples are recorded with a UV-550 spectrophotometer. 1HNMR spectrum of SBR and modified SBR are recorded on a Brucker, FT NMR $250 \mathrm{MHz}$ spectrophotometer. Differential scanning calorimetry (DSC) analysis has performed on a Perkin Elmer 7 series differential scanning calorimeter at a heating rate of $5^{\circ} \mathrm{C} / \mathrm{min}$. TGA is carried out with a Shimadzu50 thermogravimetric analyzer at a heating rate of $10^{\circ} \mathrm{C} / \mathrm{min}$ in a dry nitrogen atmosphere.

The flame resistance is measured with a Stanton Redcroft FTA flammability unit according to ASTM D 2863-77. Tensile strength of the unvulcanized sample is determined according to ASTM D 412-92 using dumbbell specimens. The test specimens are punched out from the sheet using C-type die. The thickness of the specimen within the gage length of the test specimen is measured using dial gage accuracy. $001 \mathrm{~mm}$. The specimen are test on a 'Tinius OLSEM' $\mathrm{H}-10 \mathrm{~K}$ series instrument at a temperature of $25 \pm 2{ }^{\circ} \mathrm{C}$ and crosshead speed of $500 \mathrm{~mm} / \mathrm{min}$.

Preparation of Nitromercurated styrene butadiene rubber (NSBR)

Addition of different functional group $\left(\mathrm{NO}_{2}\right.$ and $\left.\mathrm{HgCl}\right)$ group to $\mathrm{SBR}$ has been carried out by nitromercuration using phase transfer catalyst, tetra butyl ammonium bromide according to the method ${ }^{19}$ and later developed by Chein et al. ${ }^{20}$. SBR is dissolved in toluene, the phase transfer catalyst is added to this and the mixture is allowed to stir. To this mercuric chloride added followed by sodium nitrite. The reaction product is separated from the solution at a regular interval and washed with hot water and cold water, until free of chlorine. The product then coagulated with isopropyl alcohol and reprecipitated from toluene solution. The modification is monitored by the determination of nitrogen content by Kjeldahl method and chlorine percentage at different times using the method of chemical analysis. The reduction in double with different stages of chemical modification is carried out through determination of iodine value. The concentration of reagents, the temperature and time of reaction are given in Table 1.

Table 1. Concentration of reagents for chemical modification SBR

\begin{tabular}{|l|c|}
\hline $\mathrm{SBR}(\mathrm{g})$ & 100 \\
\hline Toluene $(\mathrm{mL})$ & 1000 \\
\hline Tetrabutyl Ammonium bromide $(\mathrm{g})$ & 2 \\
\hline $\mathrm{HgCl}_{2}(\mathrm{~g})$ & 5 \\
\hline $\mathrm{NaNO}_{2}(\mathrm{~g})$ & 5 \\
\hline Time $(\mathrm{h})$ & $1-12$ \\
\hline Temperature $\left({ }^{\circ} \mathrm{C}\right)$ & $30 / 60 / 80$ \\
\hline
\end{tabular}




\section{RESULTS AND DISCUSSION}

Effect of time and temperature on chemical modification in SBR

The percentages of chlorine versus time at different temperatures are given in Figure 1. The nitromercuration is fast in the initial stages but decreases at later stages of the reaction. The rate of reaction almost levels off after $10 \mathrm{~h}$ of reaction. The rate of reaction and the chlorine content increases with the temperature of the reaction. As far as the initial stage of the reaction is concerned, the reaction is extremely fast at $80^{\circ} \mathrm{C}$.

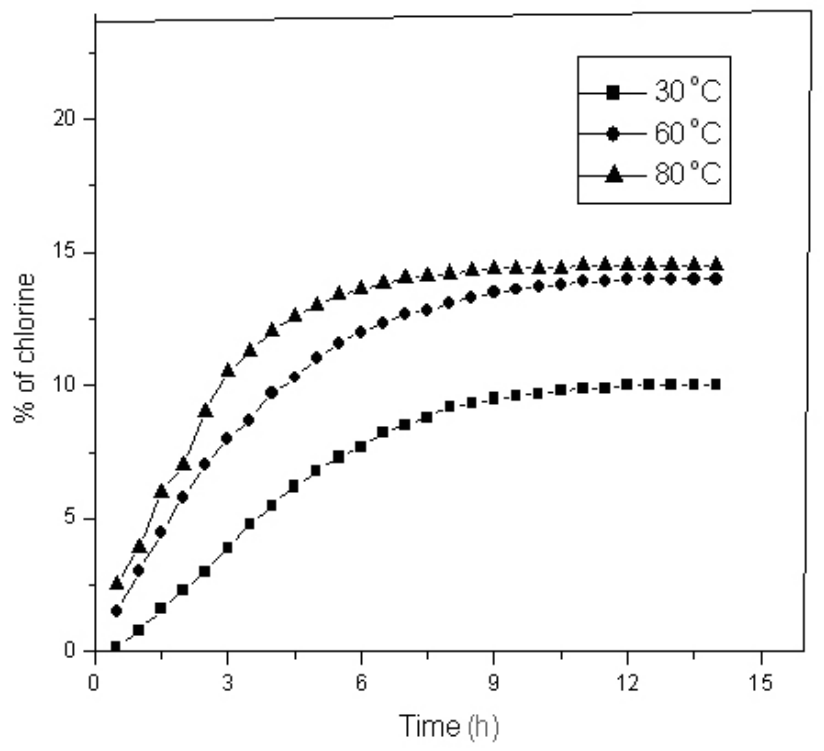

Figure 1. Plot of percentage of chlorine versus time, at temperature of 30 , 60 and $80{ }^{\circ} \mathrm{C}$

Figure 2 shows the change in percentage of chlorine $\log \left(\mathrm{c}_{\alpha}-\mathrm{c}_{\mathrm{t}}\right)$ versus time, where $\mathrm{c}$ in the maximum chlorine percentage obtained at the particular temperature and $c_{t}$ is the percentage of chlorine at any time t. Linearity of the plot shows that the modification reaction proceeds according to first order kinetics. Rate constants $(\mathrm{k})$ of the reaction calculated are $16.71 \times 10^{-2} \mathrm{~S}^{-1}, 17.97 \times 10^{-2} \mathrm{~S}^{-1}$ and $21.98 \times 10^{-2} \mathrm{~S}^{-1}$ at 30,60 and $80^{\circ} \mathrm{C}$ respectively. The activation energy of the reaction calculated from the linear plot of $\log \mathrm{K}$ versus $1 / \mathrm{T}$ (where $\mathrm{K}$ is the rate constant and $\mathrm{T}$ is the temperature in $\mathrm{K}$ ) is found to be $104.8 \mathrm{~kJ} / \mathrm{mol}$.

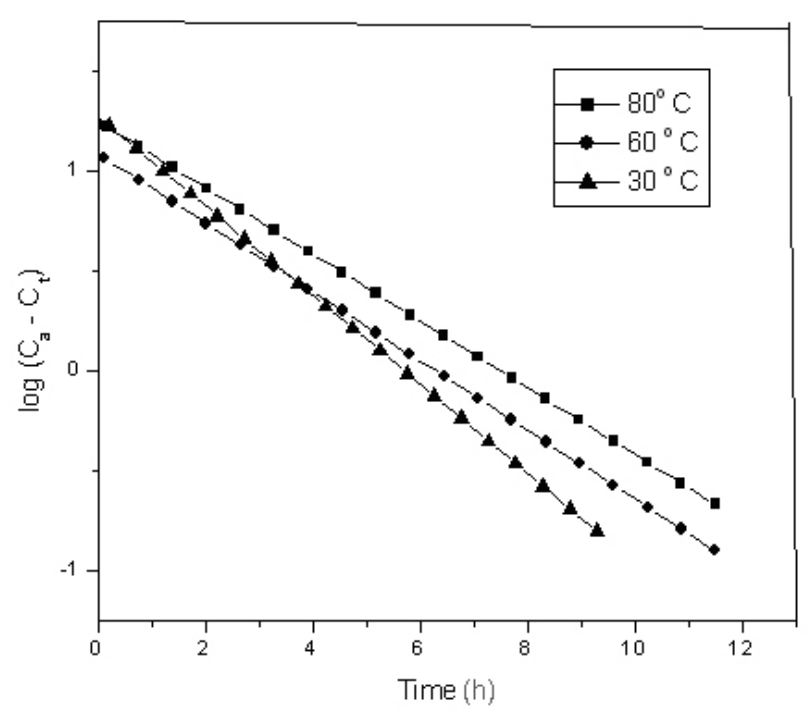

Figure 2. Plot of $\log \left(\mathrm{C}_{\alpha}-\mathrm{C}_{\mathrm{t}}\right)$ versus time for chemically modified of SBR

\section{Nitrogen content of chemically modified SBR}

The percentage of nitrogen content in the modified SBR's is given in the Table 2. As far as the 2 hour reaction concerned there is a slight change in the concentration of nitrogen with increase in temperature. When the reaction reaches to four hours there is a sharp increase in the concentration of nitrogen content. Among the three reaction conditions $80^{\circ} \mathrm{C}$ samples exhibit the maximum concentration of nitrogen content. This clearly indicates that nitromercuration reaction increases with increasing the time of reaction.

Table 2. The percentage of nitrogen content after nitromercuartion of SBR

\begin{tabular}{|l|c|c|c|}
\hline & \multicolumn{3}{|c|}{$\%$ of Nitrogen } \\
\hline Time of reaction (h) & $30^{\circ} \mathrm{C}$ & $60^{\circ} \mathrm{C}$ & $80^{\circ} \mathrm{C}$ \\
\hline 0.5 & 2.01 & 3.31 & 3.63 \\
\hline 1 & 2.56 & 3.92 & 4.24 \\
\hline 1.5 & 3.012 & 4.72 & 5.66 \\
\hline 2 & 3.421 & 5.41 & 5.61 \\
\hline 2.5 & 3.92 & 6.24 & 7.46 \\
\hline 3 & 4.52 & 6.90 & 8.92 \\
\hline 3.5 & 4.74 & 7.42 & 9.62 \\
\hline 4 & 4.82 & 7.96 & 10.1 \\
\hline
\end{tabular}

Iodine value of modified SBR at different time and temperature

The iodine value of the nitromercurated SBR's are given in the Table 3. It is observed from the table that as the reaction increases two hour, there is a small change in the iodine value with increase in temperature, where as the reaction proceeds after two hours shows a sharp decrease in iodine value. Among the three reaction conditions $80^{\circ} \mathrm{C}$ samples exhibit maximum decrease in iodine value. This clearly indicates that nitromercuration reaction becomes more prominent at 4 hours, which leads to a greater reduction in double bond.

Table 3. Iodine value of SBR and modified SBR.

\begin{tabular}{|c|c|c|c|}
\hline \multirow{2}{*}{$\begin{array}{c}\text { Time of reaction } \\
(\mathrm{h})\end{array}$} & \multicolumn{3}{|c|}{ Iodine value } \\
\cline { 2 - 4 } & $30{ }^{\circ} \mathrm{C}$ & $60{ }^{\circ} \mathrm{C}$ & $80{ }^{\circ} \mathrm{C}$ \\
\hline SBR & 522.9 & - & - \\
\hline 0.5 & 464.6 & 388.0 & 342.2 \\
\hline 1 & 442.6 & 356.0 & 323.3 \\
\hline 1.5 & 406.2 & 348.2 & 303.1 \\
\hline 2 & 373.1 & 338.7 & 291.7 \\
\hline 2.5 & 362.1 & 318.4 & 262.2 \\
\hline 3 & 379.0 & 308.9 & 236.9 \\
\hline 3.5 & 319.1 & 256.4 & 206.2 \\
\hline 4 & 296.0 & 249.8 & 180.3 \\
\hline
\end{tabular}

Characterization of modified SBR

\section{FTIR characterization}

FTIR spectra of SBR and modified SBR are given in Figure 3. It is apparent that the presence of $\mathrm{C}-\mathrm{H}$ stretching $\left(2930\right.$ and $\left.2944 \mathrm{~cm}^{-1}\right) \mathrm{CH}_{2}$ in plane deformation $\left(1448 \mathrm{~cm}^{-1}\right),-\mathrm{CH}_{2}$ wagging motion $\left(1376 \mathrm{~cm}^{-1}\right)$ and trans $\mathrm{C}=\mathrm{C}$ stretching $\left(1000 \mathrm{~cm}^{-1}\right)$. Typical styrene absorption occurs at $750 \mathrm{~cm}^{-1}$ and 963 $\mathrm{cm}^{-1}(\mathrm{C}-\mathrm{H}$ out of plane deformation of vinyl), nitromercurated samples shows the presence of chlorination band: $\mathrm{C}-\mathrm{Cl}$ stretching $\left(679 \mathrm{~cm}^{-1}\right)^{21}$. Furthermore, there appears a new absorption peaks at $1640 \mathrm{~cm}^{-1}$ is due to antisymmetric NO stretch. Otherwise with increase in the duration of chemical reaction, there is a progressive reduction in the double bond concentration and corresponding increase in the concentration of $\mathrm{C}-\mathrm{Cl}$ and $\mathrm{NO}_{2}$ bands, whereas the styrene concentration remains almost unchanged. Hence it can be inferred that it is the double bond ${ }^{22}$ of butadiene that take part in the chemical modification. Therefore the chemical modification with increase in temperature leads to an increase in polarity in SBR due to the creation of $\mathrm{C}-\mathrm{Cl}$ and $\mathrm{N}=\mathrm{O}$ groups. The proposed reaction is shown in Scheme 1 . 


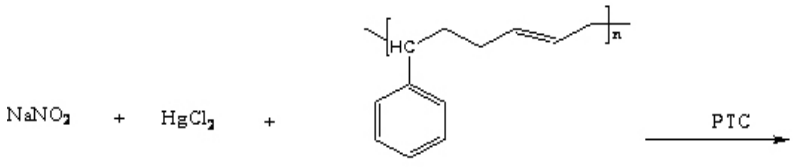<smiles>CC(C)CCC(C(C)C)C(c1ccccc1)C(F)(F)F</smiles>

$\mathrm{NaCl}$

Scheme 1. Schematic representation for the preparation of chemically modified SBR.

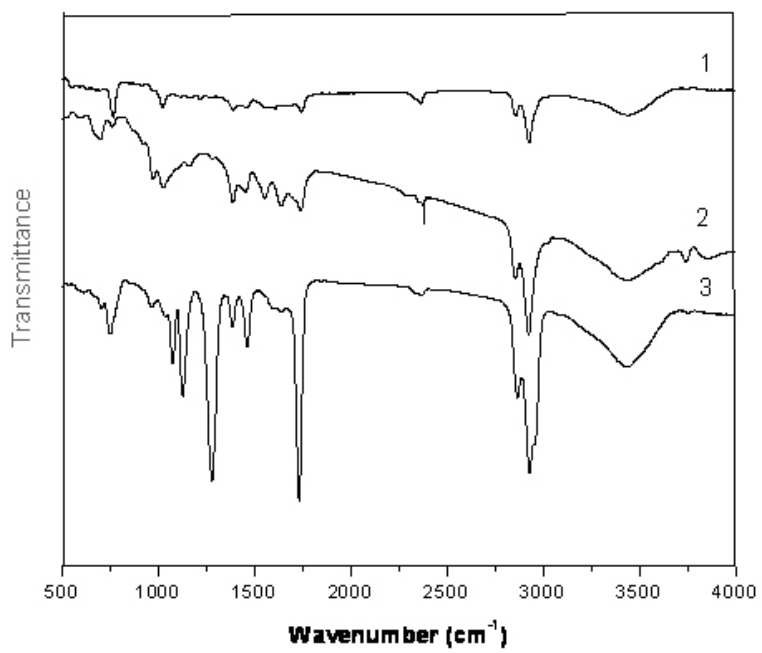

Figure 3. FTIR Spectra of thin films of (1) SBR (2) nitromercurated SBR of $4 \%$ and (3) $9 \%$ chlorine.

\section{UV spectroscopy}

UV spectra of SBR and modified SBR (NSBR) with different chlorine content are shown in the Figure 4. It is clear that as temperature is increased, a hypsochromic shift occurs that is, a shift to higher energy or shorter wavelength. The hypsochromic shift is due to the decrease in the extent of double bonds.

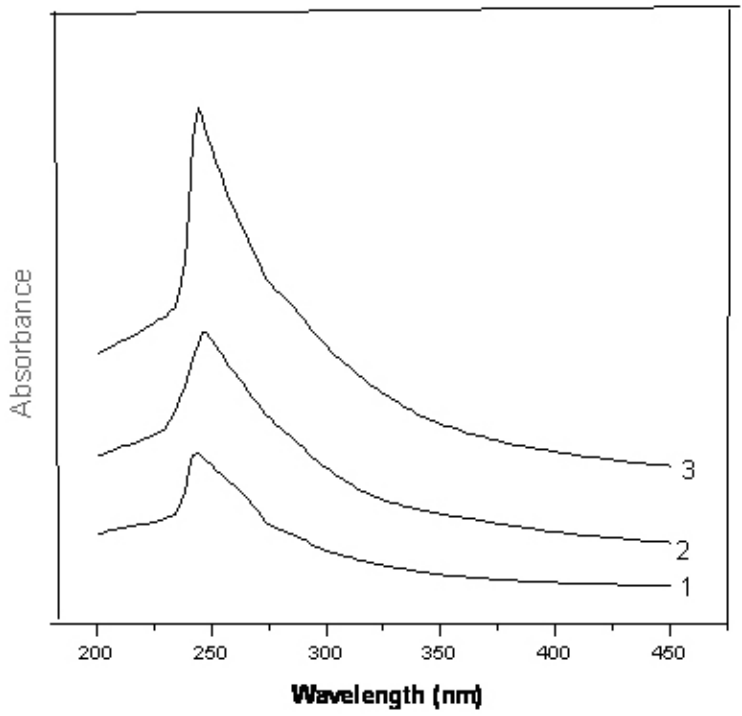

Figure 4. UV spectra of (1) SBR (2) $3 \%$ (3) $6 \%$ chlorine containing

\section{FT ${ }^{1} \mathrm{H}$ NMR Characterization}

The ${ }^{1} \mathrm{H}$ NMR spectra recorded for 3 and $6 \%$ chlorine containing modified SBR are shown in Figure 5. The singlet at 7.3-7 ppm corresponds to the hydrogen is due to the symmetric aromatic proton. The two singlet at 2 and 1.4 ppm each corresponding to a single proton are due to the unsaturated methine hydrogen $(-\mathrm{CH}=)$ of butadiene moiety. The triplet at the region 1.4 to $1.9 \mathrm{ppm}$ is due to the proton of $-\mathrm{CH}-\mathrm{Cl}$. The singlet peak obtained at $0.9 \mathrm{ppm}$ in SBR is due to the presence of tertiary hydrogen atom. Evidence showing addition reaction occurring is provided by the gradual decrease in the peak of $(=\mathrm{CH}-)$ and the increase in intensity of the extra peak at $2.3 \mathrm{ppm}$, due to proton of $\mathrm{NO}_{2}$ attached carbon atom. Thus the NMR spectrum confirms the formation of $\mathrm{NO}_{2}$ and $\mathrm{Cl}$ group in $\mathrm{SBR}$.

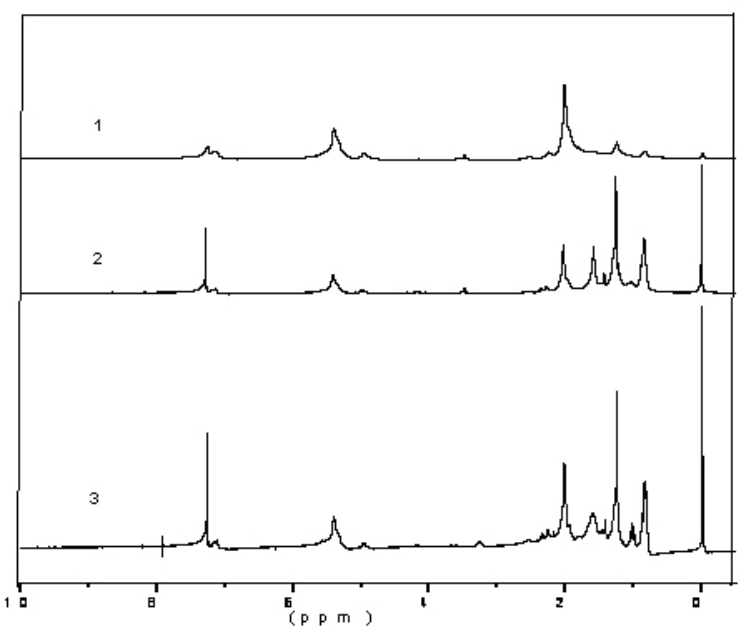

Figure 5. FT ${ }^{1}$ HNMR spectra of (1) SBR (2) modified SBR of 3\% and (3) $6 \%$ chlorine

\section{Differential scanning calorimetry}

Figure 6 demonstrated the DSC thermograms of SBR (1) and nitromercurated SBR with 3\% (2) $6 \%$ (3) and 9\% chlorine content. The thermal transition at $-58^{\circ} \mathrm{C}$ is the glass transition temperature (Tg) of the SBR. The overall appearance of the thermograms of nitromercurated samples ( curve $2 \& 3$ ) is similar to the case of unmodified polymer. However there is a shift in the Tg occurs to the right as the level of nitromercuration increases. Modified SBR with $3 \% \mathrm{Cl}$ shows a clear thermal transition at $-56^{\circ} \mathrm{C}$ whereas $6 \% \mathrm{Cl}$ containing polymer shows the thermal transition at $-54^{\circ} \mathrm{C}$. This observation reveals that as the level of nitromercuration increases $\mathrm{Tg}$ decreases. The lower $\mathrm{Tg}$ on nitromercuration indicates flexibility of the chain due to replacement of the rigid double bonds in the backbone of freely rotating single bonds.

The results obtained above are different from those obtained from the modified SBR with 9\% chlorine (curve 4). It is obvious from the figure that in addition to the $\mathrm{Tg}$ of SBR signal at $-54^{\circ} \mathrm{C}$, there appears an endothermic peak at around $-25^{\circ} \mathrm{C}$. This indicates that during nitromercuration, there are structural changes, which can lead to crystallization at low temperature ${ }^{23}$. As the modification proceeds, greater amount of $\mathrm{Cl}$ and $\mathrm{NO}_{2}$ groups are incorporated into butadiene units leading to increased polar interaction. The presence of specific groups which produce strong intermolecular bonds is one of the contributing factors for the development of low temperature crystallization ${ }^{24}$. 


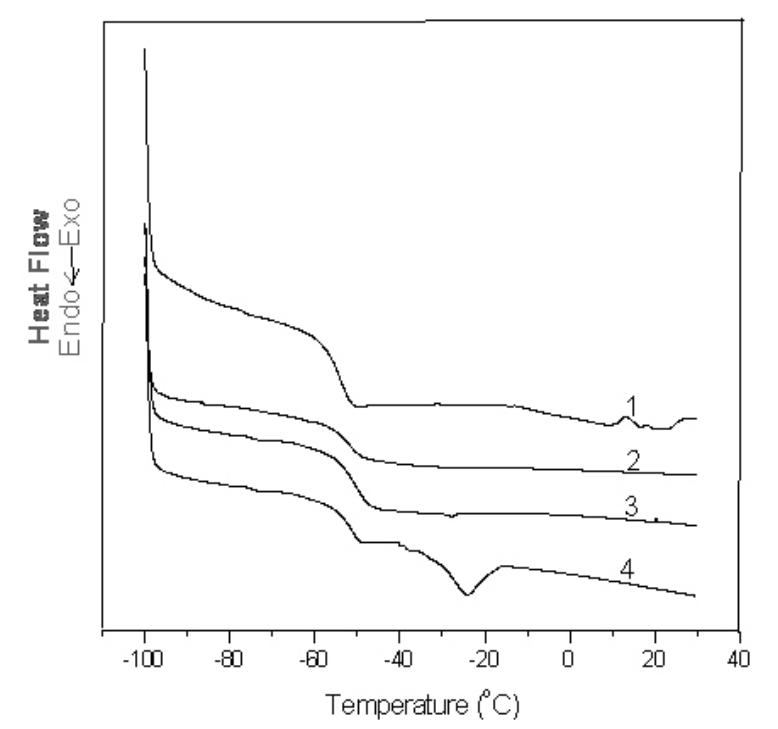

Figure 6. DSC thermograms of (1) SBR (2) modified SBR of 3\% (3) $6 \%$ (4) $9 \%$ chlorine content.

\section{Thermogravimetric analysis}

The thermograms of SBR and modified SBR's are given in the Figure 7. Pure SBR shows single-stage decomposition at a temperature of initiation of $414^{\circ} \mathrm{C}$. At low level of modification (curve 2 ) the therogarvimetric analysis curve of the modified SBR is similar to the unmodified SBR. Since under these conditions thermal degradation not yet started. On the contrary, at higher level of modification the mechanism of thermal degradation is very different. The modified polymer exhibits a two-stage degradation mechanism (curve $4 \& 5$ ). The first decomposition begins at $210^{\circ} \mathrm{C}$ and second at $414{ }^{\circ} \mathrm{C}$. The weight loss in the first stage of decomposition is due to the chlorine and $\mathrm{NO}_{2}$ group attached to the main chain of butadiene moiety and second is attributed to the degradation of the polyene residue.

The time taken for a 50\% weight drop for SBR and modified SBR are presented in the Table 4 . It is apparent from the table that the difference in thermal stability between the nitromercurated polymer is due to the difference in viscosity of the polymer, which affects the diffusion rate of volatile degradation product within the sample and partly due to the difference in the level of modification

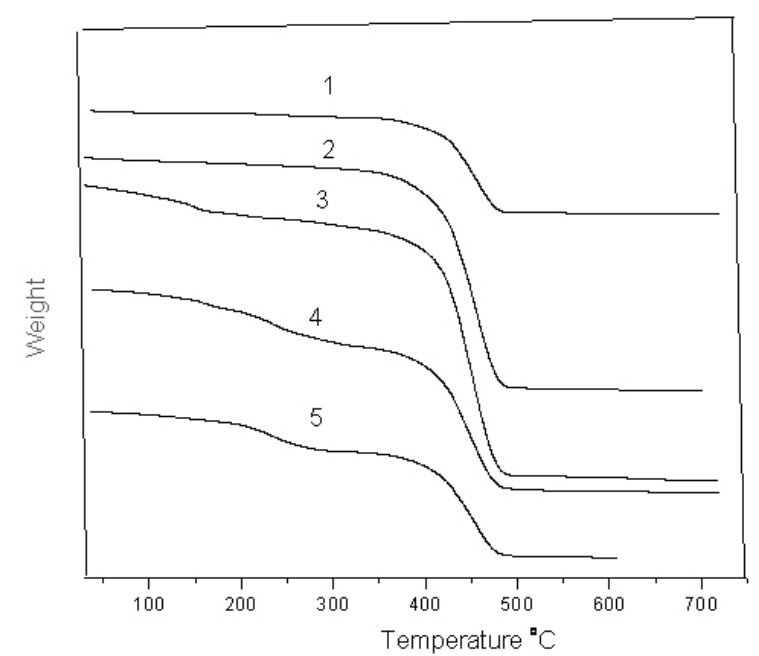

Figure 7. TGA of (1) SBR (2) chemically modified SBR of $1 \% \mathrm{Cl}$ (3) $3 \%$ (4) $6 \%$ (5) $9 \%$ chlorine content.
Table 4. Time taken for $50 \%$ weight drop for SBR and NSBR.

\begin{tabular}{|l|c|c|}
\hline \multicolumn{1}{|c|}{ Material } & Curve * & $\begin{array}{c}\text { Time for 50\% weight drop } \\
(\mathrm{min})\end{array}$ \\
\hline SBR & 1 & 44.3 \\
\hline Modified SBR $(1 \% \mathrm{Cl})$ & 2 & 44.2 \\
\hline Modified SBR $(3 \% \mathrm{Cl})$ & 3 & 44.1 \\
\hline Modified SBR $(6 \% \mathrm{Cl})$ & 4 & 43.7 \\
\hline Modified SBR $(9 \% \mathrm{Cl})$ & 5 & 42.2 \\
\hline
\end{tabular}

* Curves taken from Figure 7

\section{Flammability behaviour}

The limiting oxygen index (LOI) (which is a direct measure of the flame resistance of the materials) of pure SBR, and modified SBR are shown in the Figure 8. When the chlorine and nitrogen containing elastomers are ignited, they could exhibit an intumescence effect, due to which the char formed thermally insulates the polymer from the flame and thus inhibits combustion. It is clear from the figure that modified SBR shows better flame resistance than that of unmodified SBR. Moreover, the LOI value increases with increasing the level of chemical modifiaction. Substances with LOI value above 20.8 are classified as relatively safe while substances with LOI less than 20.8 , which continue to burn in oxygen deficient air, are not safe as building material ${ }^{25}$. Thus, modified SBR can be recommended as a substitute for building materials because these materials will be self-extinguishing even if ignited.

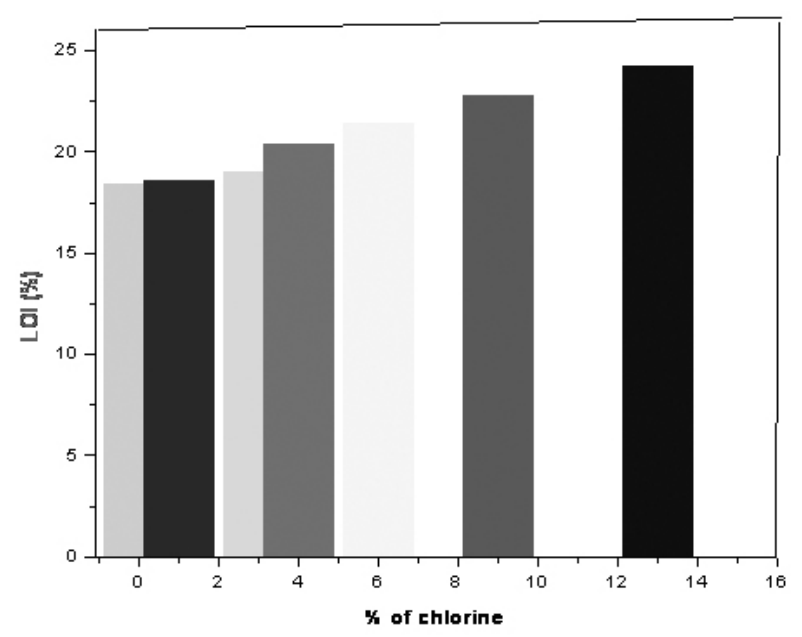

Figure 8. Variation of limiting oxygen index value (LOI) of different $\%$ of chlorine containing SBR.

\section{Tensile Strength}

The tensile strength of the SBR and nitromercurated SBR (3, 6 and 9 $\%$ chlorine) are given in Table 5 . The tensile strength and maximum elongation of the samples increases progressively as the level of nitromercuration increases. It also reveals that the tensile strength of modified SBR is much more times greater than that of pure SBR. The excellent tensile strength to the modified SBR is due to a series of inter and intramolecular interaction such as hydrogen bonding, co-ordinate bond formation between the group such as nitro, mercuric, chloro and double bond etc., 
Table 5.Tensile strength of SBR and NSBR with different level of modification.

\begin{tabular}{|c|c|c|c|}
\hline Materials & $\begin{array}{c}\text { Tensile strength } \\
(\mathrm{Mpa})\end{array}$ & $\begin{array}{c}\text { Maximum } \\
\text { elongation } \\
(\%)\end{array}$ & $\begin{array}{c}\text { Increase in } \\
\text { tensile strength } \\
(\%)\end{array}$ \\
\hline SBR & 0.226 & 3.750 & 84.5 \\
\hline NSBR $(3 \% \mathrm{Cl})$ & 1.462 & 64.2 & 91.9 \\
\hline NSBR $(6 \% \mathrm{Cl})$ & 2.798 & 110.4 & 94.6 \\
\hline NSBR $(9 \% \mathrm{Cl})$ & 4.256 & 190.7 & \\
\hline
\end{tabular}

\section{CONCLUSIONS}

Chemical modification of SBR is carried out through nitromercuration by the addition of sodium nitrite and mercuric chloride using phase transfer catalyst. The activation energy of the chemical reaction is calculated from the time-temperature data on the chemical reaction by the measurement of the percentage of chlorine indicated that the reaction proceeded according to firstorder kinetics. The percentage of nitrogen calculated using Kjeldahl method also shows a gradual increase in nitrogen content with time and temperature. The iodine value calculated shows a steady decrease in double bond concentration. The chemical modification is characterized by FTIR, UV and NMR spectroscopic studies. These studies revealed the attachment of chlorine and $\mathrm{NO}$ to the double bond of butadiene. The glass transition temperature of the modified SBR is studied using DSC. As the level of modification increases $\mathrm{Tg}$ decreases. The basic decomposition pattern and thermal stability of the samples are carried out using TGA. The flame resistances of the chemically modified samples are analyzed and find that as the level modification increases the tendency of ealstomeric material to burn decreases. Chemical modification imparts excellent green strength to SBR which is almost several times greater than that of pure SBR. Studies on introducing other functionalisable smart polymers with optoelectronic properties in the polymer chain are underway.

\section{REFERENCES}

1. J. C. Brosse, I. Campistron, D. Derouet, A. El. Hamdaoui, S. Houdayer, D. Reyx, S. Ritoit-Gillier, J. Appl. Polym. Sci. 78, 1461, (2000)

2. S. Yamashita, K. Kodama, Y. Ikeda, S. Kohjiya, J. Polym. Sci. Part A. Polym. Chem. 31, 2437, (1993)

3. A. Rouilly, L. Rigal, G. G. Gilbert, Polymer 45, 7813, (2004)

4. D. Derouet, Q. N. Tran, H. H Thuc, Eur. Polym. J. 43, 1806, (2007)

5. A.F. Halasa, J.M. Massie, R. J. Ceresa The chemical modification of polymers, Science and Technology of Rubber, $3^{\text {rd }}$ edn., 2005

6. J. Tyczkowski, I, Tyczkowski, B. Wozniak, Surface \& Coatings Tech. 174, 849, (2003)

7. M. H. Zhou, W.J. Cho, J. Appl. Polym. Sci. 89, 1818, (2003)

8. J. Peng, Encyclopedia Chem Process 1,2871, 2005

9. N. T. McManus, L.G. Rempel, Polym. Review 35, 239, (1995)

10. C. M. Leir C. M. J. E. Stark, J. Appl. Polym. Sci. 38,1535, (1989)

11. X. Chen, E. Ruckenstein, J. Polym. Sci. Part A: Polym Chem. 38, 1662, (2000)

12. A. A.Yakubovich, B.I. Nakhmanovich, G. I. Litvinenko, Polymer 43, 7093, (2002)

13. A. F. Halasa, B. Hsu, C. Jasiunas, Polymer 46, 4166, (2005)

14. R.E. Lyon, L. Speitel, R.N. Walters, S. Crowley, Fire Mater. 27, 195, (2003)

15. M. T. Ramesan, R. Alex, J. Appl. Polym. Sci. 68, 153, (1998)

16. W. Jincheng, C. Yuehui, J. Elast. Plast. 39, 33, (2007)

17. K. T. Varughese, P.P. De, S.K. De, J. Fire Sc. 7, 94, (1989)

18. O. Zhou, W. Yang, Q. Wu, B. Yang, H. Jinman, J. Shen, Eur. Polym. J. 36, 1735, (2000)

19. E. J. Corey H. Estreicher, J. Amer. Chem. Soc. 100, 6294 (1978)

20. J. C. W. Chien, T. Kohara, C. P. Lillya, T. Sarubbi, B. H. Su, R.S. Miller, J Polym. Sci. Polym. Chem. Edn. 18, 2723, (1980)

21. S. A. Liebman, B.J. Gudzinowicz, Anal. Chem. 33, 931, (1961)

22. H. Mayr, U.W. Heigl, Angew. Chem. Int. Ed. Engl. 24, 579, (1985)

23. M. T. Ramesan, R. Alex, Kautsch. Gummi Kunstst. 10, 596, (2000)

24. R. Stadler, J. Burgert, Makromol. Chem. 187, 1681, (1986)

25. M. T. Ramesan, J. Polym. Res. 11, 333, (2004). 